\title{
Nocardia otitidiscaviarum (GAM-5) induces parkinsonian-like alterations in mouse
}

F.J. Díaz-Corrales ${ }^{1}$, C. Colasante ${ }^{1}$, Q. Contreras ${ }^{1}$, M. Puig ${ }^{1}$, J.A. Serrano ${ }^{1}$,

L. Hernández ${ }^{1}$ and B.L. Beaman ${ }^{2}$

\author{
${ }^{1}$ Laboratorio de Fisiología de la Conducta, Facultad de Medicina, \\ Universidad de Los Andes, Mérida, Venezuela \\ 2Department of Medical Microbiology and Immunology, \\ University of California School of Medicine, Davis, CA, USA
}

\section{Correspondence \\ C. Colasante \\ Laboratorio de Fisiología de \\ la Conducta \\ Facultad de Medicina \\ Universidad de Los Andes \\ Mérida 5101 \\ Venezuela \\ Fax: +58-274-263-8304 \\ E-mail: cesare@ula.ve}

Research supported by CDCHT, University of Los Andes (M-603-97-03-E).

Received May 28, 2003

Accepted January 5, 2004

\section{Abstract}

Parkinson's disease, a major neurodegenerative disorder in humans whose etiology is unknown, may be associated with some environmental factors. Nocardia otitidiscaviarum (GAM-5) isolated from a patient with an actinomycetoma produced signs similar to Parkinson's disease following iv injection into NMRI mice. NMRI mice were infected intravenously with a non-lethal dose of $5 \times 10^{6}$ colony forming units of $N$. otitidiscaviarum (GAM-5). Fourteen days after bacterial infection, most of the 60 mice injected exhibited parkinsonian features characterized by vertical head tremor, akinesia/bradykinesia, flexed posture and postural instability. There was a peak of nocardial growth in the brain during the first $24 \mathrm{~h}$ followed by a decrease, so that by 14 days nocardiae could no longer be cultured. At $24 \mathrm{~h}$ after infection, Gram staining showed nocardiae in neurons in the substantia nigra and occasionally in the brain parenchyma in the frontal and parietal cortex. At 21 days post-infection, tyrosine hydroxylase immunolabeling showed a $58 \%$ reduction of tyrosine hydroxylase in the substantia nigra, and a 35\% reduction of tyrosine hydroxylase in the ventral tegmental region. Dopamine levels were reduced from $110 \pm 32.5$ to $58 \pm 16.5 \mathrm{ng} / \mathrm{mg}$ protein ( $47.2 \%$ reduction) in brain from infected mice exhibiting impaired movements, whereas serotonin levels were unchanged $(191 \pm 44$ protein in control and 175 $\pm 39 \mathrm{ng} / \mathrm{mg}$ protein in injected mice). At later times, intraneuronal inclusion bodies were observed in the substantia nigra. Our observations emphasize the need for further studies of the potential association between Parkinson's disease or parkinsonism-like disease and exposure to various nocardial species.

\section{Introduction}

Parkinsonism is a complex neurological syndrome caused by lesions in the basal ganglia, especially in the substantia nigra (1). This syndrome can be separated into
Key words

- Nocardia otitidiscaviarum (GAM-5)

- Parkinson's disease

- Substantia nigra

- Bradykinesia

- Dopamine

- Tyrosine hydroxylase 
Many factors such as infections, toxins, drugs, brain tumors, head trauma, vascular and metabolic alterations, among others, can induce parkinsonian signs in humans (1). Nevertheless, the etiology of PD is still unknown $(4,5)$.

Post-encephalic parkinsonism was discovered as a consequence of an epidemic of sporadic encephalitis lethargica, first described by von Economo in 1917 (6). This epidemic gave rise to the belief that PD might be associated with an infectious agent such as a virus, especially Epstein Barr virus, influenza virus, coronavirus and Japanese encephalitis virus (7-12). Since the 1980's, several additional microorganisms such as Borrelia burgdorferi, Haemophilus influenzae, Corynebacterium diphtheriae, Cryptococcus neoformans, Mycoplasma pneumoniae and Helicobacter pylori (1316) have been postulated as agents that could be associated etiologically with PD or another kind of parkinsonism. However, these studies have been based on clinical reports and most of these have not been experimentally implicated as a cause of PD in animal models.

Currently, there is a well-documented animal model for PD in mice, using the GUH-2 strain of Nocardia asteroides (17). This Nocardia was isolated from a kidney of a patient who died of systemic nocardiosis (18). The genus Nocardia consists of Grampositive bacteria that have a branched filamentous growth pattern. During growth, these filamentous bacteria become fragmented into coccoidal and bacillary forms (19). The nocardiae are commonly isolated from soils and aquatic sources (20). Some species of Nocardia produce different diseases including central nervous system nocardiosis $(19,21)$.

Experimental infection of mice with the filamentous form of $N$. asteroides, GUH-2, results in a variety of PD-like symptoms. These mice are characterized by tremor, rhythmic vertical head shakes when the ani- mal is quiescent, circular spinning when held by the tail, and postural instability $(17,20,22)$. The bacteria were localized in different brain regions $(23,24)$, the neurological signs were inhibited by L-dopa treatment, tyrosine hydroxylase activity was reduced, and characteristic cytoplasmic inclusions were detected (17). Furthermore, GUH-2 induces a specific reduction in dopamine levels and alters dopamine metabolism in the neostriatum similar to that characteristic of PD in humans (25).

We discovered that other species of Nocardia induced impaired movements in mice following a sublethal infection. Therefore, we proposed to determine whether strain GAM-5 of Nocardia otitidiscaviarum isolated from a human mycetoma (26) could induce in mice histopathological and neurological parkinsonian manifestations similar to those described by Kohbata and Beaman (17).

\section{Material and Methods}

\section{Bacterial isolation}

The strain of $N$. otitidiscaviarum (GAM5) was isolated from a lesion of a patient with an actinomycetoma treated at the "Antonio María Pineda" Central Hospital of Barquisimeto, Venezuela (26). The strain was cultured aerobically in $50 \mathrm{ml}$ of brain heart infusion (BHI) broth (Difco Laboratories, Franklin Lakes, NJ, USA) at $37^{\circ} \mathrm{C}$ with rotational shaking (150 rpm) for 5 days, the culture was centrifuged for $30 \mathrm{~min}$ at 3,000 rpm and the bacterial pellet was resuspended in $50 \mathrm{ml}$ of BHI broth. The suspension was then centrifuged for $15 \mathrm{~min}$ at $1,500 \mathrm{rpm}$ and $5 \mathrm{ml}$ of the supernatant was adjusted in order to reach 0.05 units of absorbance at $580 \mathrm{~nm}$. The suspension was then used to prepare the inoculum as described below.

\section{Inoculum}

Five milliliters of the culture was trans- 
ferred to $50 \mathrm{ml}$ of fresh BHI broth and incubated at $37^{\circ} \mathrm{C}$ with rotational shaking $(150$ rpm) for $18 \mathrm{~h}$ in order to obtain a log-phase culture with filamentous bacteria. The nocardial culture was centrifuged for $5 \mathrm{~min}$ at $500 \mathrm{rpm}$ and the pellet was resuspended in $10 \mathrm{ml} 0.85 \%$ saline solution.

\section{Nocardial infection}

Female NMRI (BioULA) mice (specific pathogen-free; 21-25 days old, and approximately $20 \mathrm{~g}$ weight) were infected by tail vein injection with a $0.1-\mathrm{ml}$ suspension (in $0.85 \%$ saline) of a log-phase culture ( $18 \mathrm{~h}$ ) of $N$. otitidiscaviarum (GAM-5). To optimize the nocardial dose that yielded a non-lethal infection, groups of mice received dilutions of the suspension $(1 / 10,1 / 100,1 / 1000)$, and the number of colony forming units (CFU) for each dilution was determined. The mice were monitored and the optimal infecting dose was determined. In all subsequent experiments, the optimal dose of $5 \times 10^{6} \mathrm{CFU}$ of $N$. otitidiscaviarum was inoculated into mice. The control mice were injected with $0.1 \mathrm{ml}$ of the saline solution alone. Mice were decapitated $2 \mathrm{~h}$ and $1,2,5,7$, and 14 days ( $\mathrm{N}=5$ mice for each group) postinfection and the brains were rapidly removed and homogenized, and dilutions (1/ 10, 1/100, 1/1000) were placed on Petri dishes followed by an overlay with BHI agar. The plates were incubated for 3 days at $37^{\circ} \mathrm{C}$ and the $\mathrm{CFU} / \mathrm{brain}$ determined as described by Kohbata and Beaman (17).

\section{Histological study}

Mice were decapitated 1 and 30 days post-infection ( $\mathrm{N}=5$ mice for each group) and the brains dissected out and fixed with $10 \%$ formaldehyde in phosphate-buffered saline (PBS) for $18 \mathrm{~h}$, dehydrated in ethanol and embedded in paraffin. Serial coronal sections ( $5 \mu \mathrm{m}$ thick) were stained with hematoxylin-eosin and the Brown and Brenn modified Gram stain (27).

\section{Tyrosine hydroxylase immunocytochemistry}

Infected (21 days post-infection) and control ( $\mathrm{N}=10$ mice per group) were anesthetized with $80 \mathrm{mg} / \mathrm{kg}$ ketamine and $12 \mathrm{mg} / \mathrm{kg}$ sodium pentobarbital and intracardially perfused with Ringer's solution followed by buffered $4 \%$ paraformaldehyde $(0.1 \mathrm{M}, \mathrm{pH}$ 7.2). The brains were dissected out and postfixed for $3 \mathrm{~h}$ in the same fixative, followed by immersion in 7, 15 and $30 \%$ buffered sucrose solution. Frozen coronal brain sections ( $25 \mu \mathrm{m}$ thick) containing the substantia nigra and the ventral tegmental area (VTA) were immunolabeled for tyrosine hydroxylase. The sections were blocked against nonspecific antibody binding using 5\% normal goat serum in $0.1 \mathrm{M}$ PBS $(150 \mathrm{mM} \mathrm{NaCl})$, followed by overnight incubation with mouse anti-tyrosine hydroxylase monoclonal antibody (Sigma, St. Louis, MO, USA) diluted $1: 4,000$ plus $3 \%$ normal goat serum in PBS at $4^{\circ} \mathrm{C}$. These sections were then incubated with anti-mouse fluorescein-conjugated IgG (Vector Laboratories, Burlingame, CA, USA) at 1:500 dilution, plus 3\% normal goat serum in PBS at room temperature for $60 \mathrm{~min}$. The samples were analyzed with an Olympus Fluoview II Scanning Laser Confocal System coupled to an Olympus IX 70 fluorescence microscope. Data acquisition was performed at 400X magnification using a single confocal setting.

\section{Neurochemical analysis}

The amount of dopamine (DA), dihydroxyphenylacetic acid (DOPAC), 5-hydroxyndolacetic acid (5-HIAA), monovanillic acid (HVA), and serotonin (5-HT) present in brain homogenates of nocardia-infected $(21$ days post-infection) and control mice ( $\mathrm{N}=5$ mice per group) was determined by high performance liquid chromatography using an apparatus equipped with an electrochemi- 
cal detector (HPLC-EC). Mice were decapitated, and the brains were immediately dissected out and placed in liquid nitrogen. After weighing, each brain was homogenized in $0.1 \mathrm{M}$ perchloric acid plus $0.1 \mathrm{mM}$ EDTA (10 $\mathrm{ml} / \mathrm{mg}$ weight) for $30 \mathrm{~s}$ and centrifuged at $12,000 \mathrm{rpm}$ for $15 \mathrm{~min}$ at $4^{\circ} \mathrm{C}$. For the DA, DOPAC, 5-HIAA, HVA, and 5-HT assays, the supernatants from the different homogenates were analyzed by HPLC-EC. Twentymilliliter samples were injected into a $20-\mathrm{ml}$ valve loop leading to a $10 \mathrm{~cm}$ long, $3.2 \mathrm{~mm}$ bore, 3 ODS phase II column (Brownlee Column, Perkin Elmer Corp., Norwalk, CT, USA). The mobile phase contained 116.8 $\mathrm{mM}$ sodium hydroxide, $144.7 \mathrm{mM}$ monochloroacetic acid, $1 \mathrm{mM}$ octanesulfonic acid, $100 \mathrm{mM}$ EDTA, $1 \mathrm{mM}$ octanesulfonic acid, and $2 \% \mathrm{v} / \mathrm{v}$ acetonitrile, with the $\mathrm{pH}$ adjusted to 3.1. The flow rate of the mobile phase was set at $1 \mathrm{ml} / \mathrm{min}$ provided by pressure generated by a single-piston pump (model $220 \mathrm{~B}$, SSI Inc., State College, PA, USA). Neurochemical detection was performed with an amperometric detector (EG\&G Princeton Application Research Corp., Princeton, NJ, USA) with the guard cell set at $+705 \mathrm{mV}$, and equipped with an $\mathrm{Ag}-\mathrm{AgNO}_{3}$ reference electrode. The order of elution was DOPAC, DA, 5-HIAA, HVA, and 5-HT, with retention times of $3.5,5.2,7.1,11.0$, and 22.0 min, respectively. The neurochemicals in each sample were measured by a ratio of unknown to standard peak heights and the results were reported as $\mathrm{ng} / \mathrm{mg}$ protein. The pellet was resuspended and its protein content determined by the Bradford's method (28). The mean values for the infected mice with neurological manifestations and for noninfected controls were compared using the $t$ test.

\section{Results}

\section{Movement abnormalities}

Different types of impaired movements developed in most of the mice inoculated with $N$. otitidiscaviarum (GAM-5). Vertical and lateral head tremor, akinesia/bradykinesia, flexed posture, deviation of the head, trunk flexion or spinning when held by the tail, postural instability, and walking in circles were the main impairments observed in the inoculated animals, whereas no control animals showed these disorders. As early as 5 days post-infection, $2.5 \%$ of the animals showed some movement impairments such as lateral head tremor, deviation of the head, spinning when held by the tail, and walking in circles (Table 1). At 7 days after infection, the number of mice showing these movement disorders increased to approximately $7.5 \%$ and other mice $(2.5 \%)$ began to show other movement disorders such as vertical head tremor, akinesia/bradykinesia, flexed posture, trunk flexion when held by the tail, and postural instability. The number of mice experiencing motor impairments continued to increase with $25 \%$ of the mice presenting

Table 1. Neurological manifestations observed in 40 mice inoculated with $5 \times 10^{6} \log$ phase CFU of Nocardia otitidiscaviarum (GAM-5).

\begin{tabular}{lcc} 
Days post-inoculation & $\begin{array}{c}\text { Vertical head tremor, akinesia/bradykinesia, } \\
\text { flexed posture, trunk flexion when held } \\
\text { by the tail, and postural instability (N (\%)) }\end{array}$ & $\begin{array}{c}\text { Lateral head tremor, deviation } \\
\text { of the head, spinning when held } \\
\text { by the tail, walking in circles (N (\%)) }\end{array}$ \\
\hline 5 & $0(0)$ & $1(2.5)$ \\
7 & $1(2.5)$ & $2(5)$ \\
14 & $4(10)^{*}$ & $2(5)$ \\
Total & $5(12.5)$ & $5(12.5)$
\end{tabular}

*One of these mice also walked in circles. 
different neurological manifestations 14 days after infection. Even though vertical head tremor, akinesia/bradykinesia, flexed posture, trunk flexion when held by the tail, and postural instability were detected at 7 days after infection, at day 14 the number of mice presenting these neurological manifestations was roughly the same as the number of mice that showed lateral head tremor, deviation of the head, spinning when held by the tail, and walking in circles. These impaired movements appeared to become stabilized at 14 days after infection, with no additional altered behaviors being noted thereafter.

\section{Growth of nocardia in the brain}

The brains of nocardia-infected NMRI mice were removed at $2 \mathrm{~h}$ and at 1, 2, 5, 7, and 14 days post-infection and the number of bacteria (CFU/brain) was quantified. At day 0, approximately $10^{3} \mathrm{CFU}$ were present in the brain (Figure 1). Then, the bacteria grew rapidly, resulting in more than a tenfold increase after one day. Two days after infection the bacterial CFU remained constant, decreasing linearly thereafter until no bacteria were detected 14 days post-infection.

\section{Histology}

Modified Brown and Brenn Gram staining of paraffin-embedded sections revealed small foci of nocardiae within the parenchyma of different brain regions at $24 \mathrm{~h}$ after intravenous (iv) inoculation. Filamentous bacteria were associated with neuronal soma while no inflammatory infiltrates were observed at these sites (Figure 2). The nocardiae were found mainly in the frontal and parietal cortex, the substantia nigra pars compacta (SNpc), the VTA, the red and subthalamic nuclei, the thalamus, and the hypothalamus. In one mouse, nocardial cells were also localized in the striatum. It is important to note that, in some cases, small inflammatory le- sions were observed in the absence of bacteria. One month after infection, intracytoplasmic hyaline-like inclusion bodies (Lewylike bodies) were observed occasionally in neurons of the SNpc, subthalamic nucleus, and cortex of mice expressing neurological manifestations (Figure 3). These spherical inclusions were approximately 5 to $10 \mu \mathrm{m}$ in diameter and consisted of two layers: a hematoxylinophilic core and a weakly eosinophilic periphery.

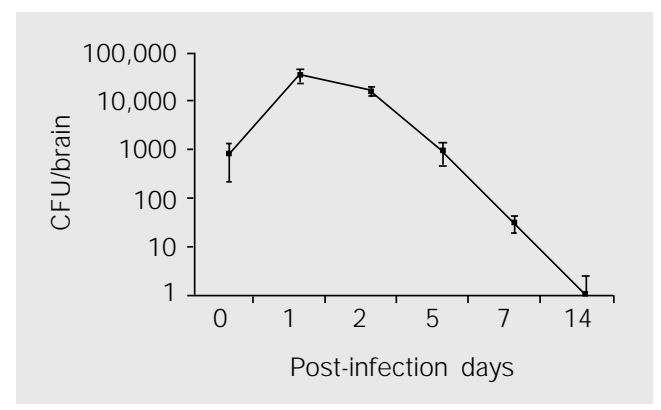

Figure 1. Growth and clearance of Nocardia otitidiscaviarum (GAM-5) in the brains of NMRI mice inoculated with $5 \times 10^{6}$ colony forming units (CFU). Data are reported as means \pm SD . Note that the ordinate scale is logarithmic.

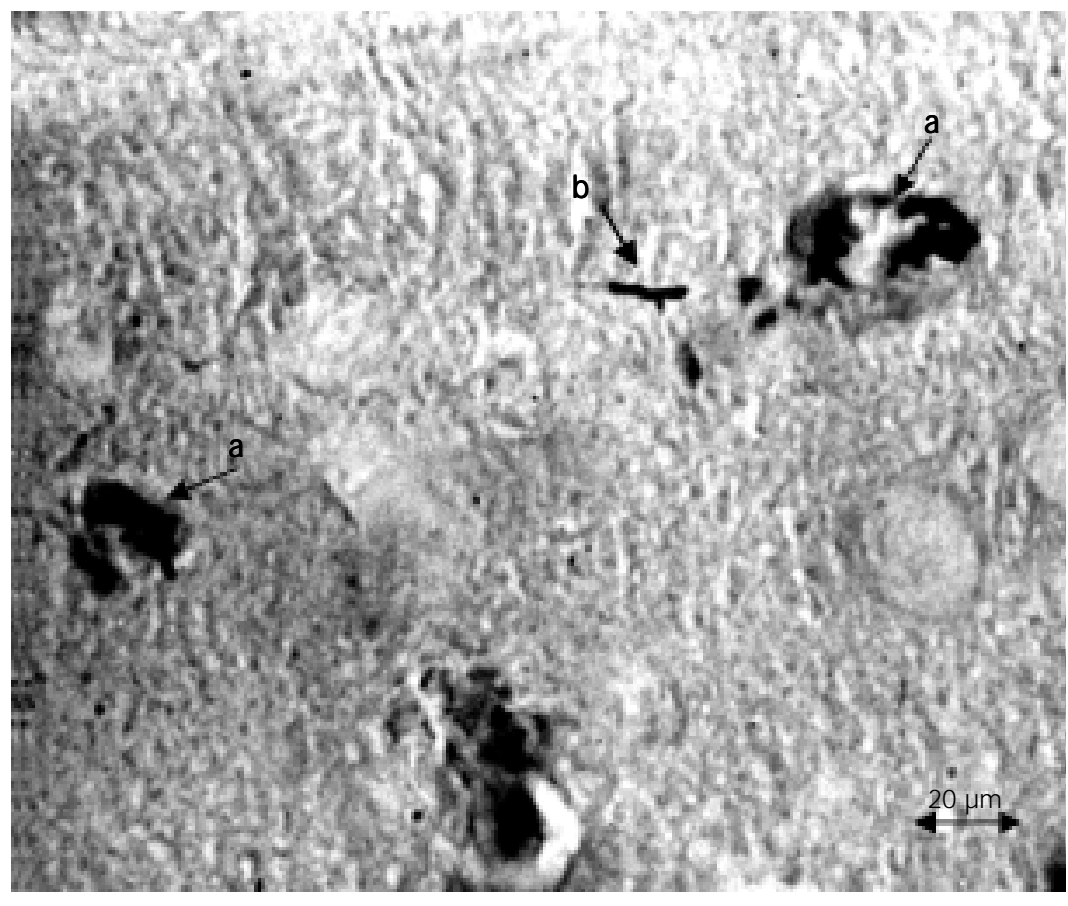

Figure 2. Micrograph of a mouse substantia nigra submitted to modified Brown and Brenn Gram staining, $24 \mathrm{~h}$ post-inoculation of $5 \times 10^{6}$ colony forming units of Nocardia otitidiscaviarum (GAM-5). a, Filaments from the bacteria inside the neuron perikaryon. $b$, Bacterial filaments in the brain parenchyma without evidence of an inflammatory response. 

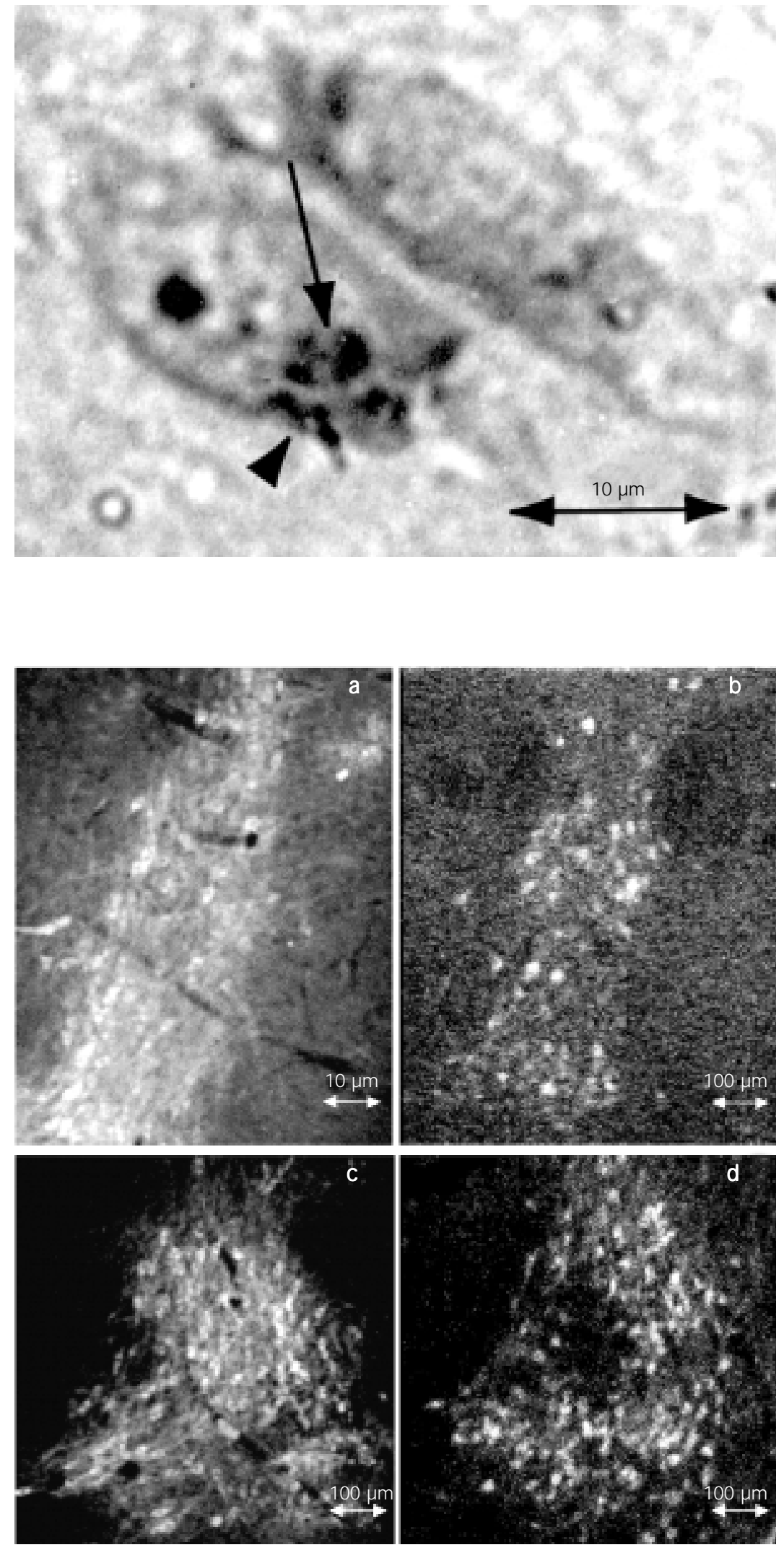

Figure 3. Micrograph of a mouse substantia nigra pars compacta stained with hematoxylin-eosin 1 month post-inoculation of $5 \times 10^{6}$ colony forming units of Nocardia otitidiscaviarum (GAM-5). A hyaline intracytoplasmatic inclusion (arrow) similar to the Lewy bodies can be seen. Note the presence of Nocardia in the neuron cytoplasm (arrowhead).

Figure 4. Tyrosine hydroxylase (TH)-labeled neurons from NMRI mice at 21 days after intravenous infection with $5 \times 10^{6}$ colony forming units of Nocardia otitidiscaviarum (GAM-5) showing neurological manifestations (experimental mice), and from control noninfected mice. Scanning confocal laser micrographs of immunofluorescent neurons from: a) substantia nigra pars compacta (SNpc) of control animals, b) SNpc of experimental animals, c) ventral tegmental area (VTA) of control animals, and d) VTA of experimental animals. Note the large decrease in the number of TH-positive neurons in the SNpc of the experimental group (b) compared to control (a), as well as a decrease in the number of TH-positive neurons in the VTA of infected mice (d) compared to control (c). 


\section{Immunohistochemistry}

Tyrosine hydroxylase immunohistochemistry was used to label catecholaminergic neurons from the SNpc and the VTA of NMRI mice 21 days after $i v$ infection with 5 x $10^{6} \mathrm{CFU} N$. otitidiscaviarum. Mice showing neurological manifestations were compared with non-infected control mice (Figure 4). In the infected mice, the mean number of tyrosine hydroxylase-positive perikarya (10 coronal sections per mouse) from the SNpc and from the VTA was reduced by 57.8 and $35.4 \%$, respectively (Figure 5). The loss of catecholaminergic neurons was greater in the SNpc than in the VTA.

\section{Neurochemical changes}

DA and its metabolites DOPAC and HVA, as well as 5-HT and 5-HIAA were measured in brain homogenates from two different groups of NMRI mice: a) non-in- fected controls and b) mice that showed movement impairments at 21 days after infection. The mean DA concentration in the brain was decreased by $47.2 \%$ in the infected mice that showed impaired movements (Figure 6). The reduction of DA in the
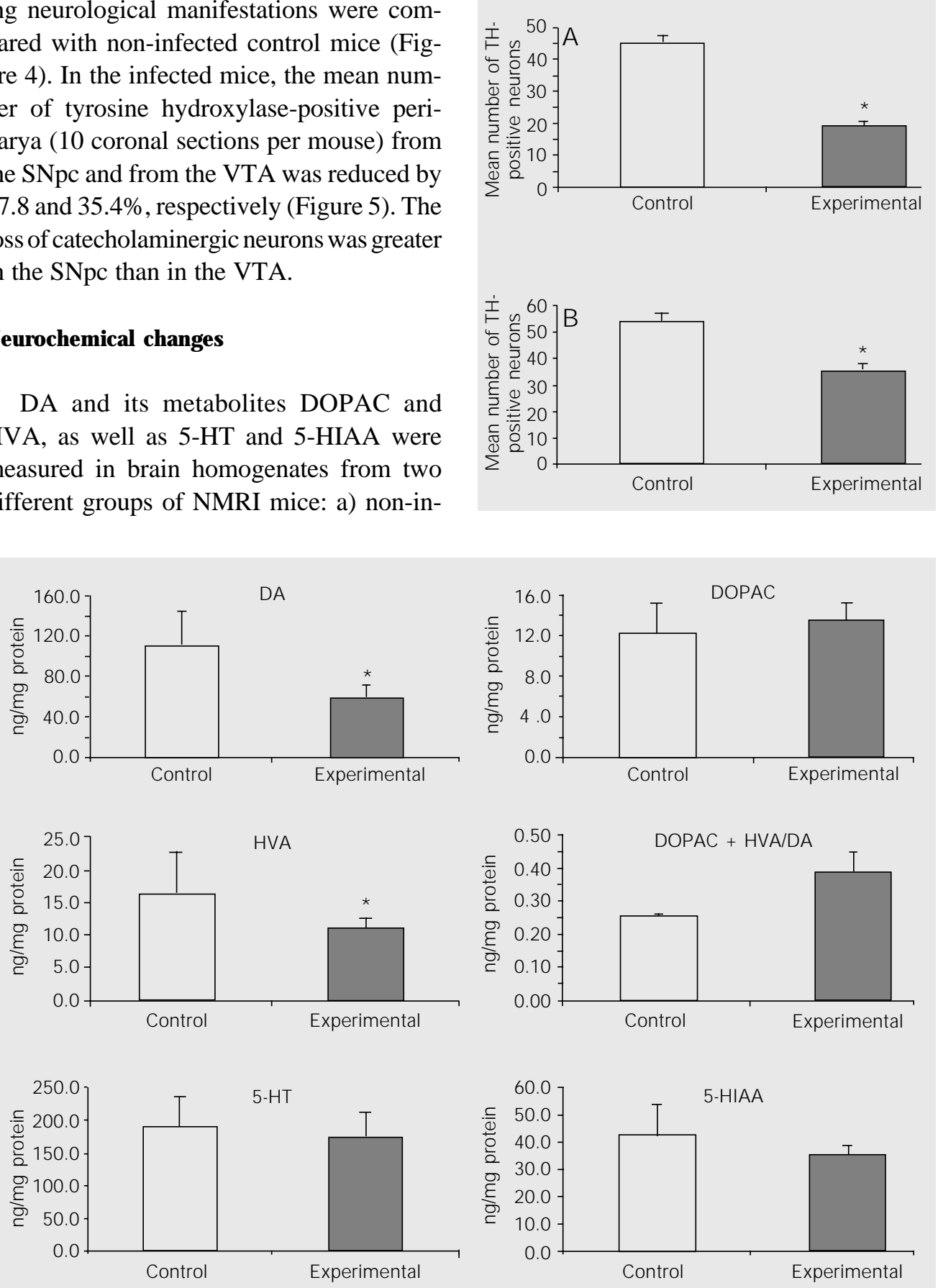

Figure 5. Number of catecholaminergic tyrosine hydroxylase (TH)-labeled neurons of the substantia nigra pars compacta (A, $\mathrm{SNpc}$ ) and of the ventral tegmental area (B, VTA) of mice 21 days post-inoculation of $5 \times 10^{6}$ colony forming units of Nocardia otitidiscaviarum (GAM-5) (experimental) and of non-infected mice (control). The small bars represent the mean \pm SEM $(* \mathrm{P}$ $<0.001$ compared to control, Student t-test). The Nocardia-infected mice showed a large reduction in the TH-positive neurons in both the SNpc and in the VTA. However, the reduction was greater in the dopaminergic SNpc neurons, i.e., $58 \%$ compared to $35 \%$ in the VTA.

Figure 6. Monoamine changes in the brain of NMRI mice at 21 days after a single intravenous injection of $5 \times 10^{6}$ colony forming units of Nocardia otitidiscaviarum (GAM-5) (experimental) and of non-infected mice (control). The small bars represent the mean \pm SEM. $* P<0.05$ compared to control (Student ttest). DA = dopamine; DOPAC = dihydroxyphenylacetic acid; DOPAC + HVA/DA = DA turnover; 5-HIAA = 5-hydroxyndolacetic acid; 5-HT = serotonin; HVA = monovanillic acid. 
group of infected mice was associated with a small, but not significant, increase in DOPAC concentration in the brain. All of the infected mice showed an approximate $32.3 \%$ reduction in HVA concentration compared to the non-infected control animals. Although the difference in DA turnover (DOPAC + HVA/ DA) between the two groups was not significant, DA turnover was higher in the infected mice. The concentrations of the neurotransmitter 5-HT and of its metabolite 5-HIAA were unchanged in nocardia-infected mice.

\section{Discussion}

The results obtained in the present study show that $N$. otitidiscaviarum (GAM-5) isolated from a patient with an actinomycetoma produced signs similar to PD following $i v$ injection into NMRI mice. The principal signs of PD are rhythmic tremor at rest, muscular rigidity, bradykinesia, and postural instability (1-4). Mice injected $i v$ with $5 \mathrm{x}$ $10^{6} \log$ phase cells of $N$. otitidiscaviarum (GAM-5) developed some of this neurological manifestations. The major motor impairments observed were vertical and lateral head tremor, akinesia/bradykinesia, flexed posture, deviation of the head, trunk flexion and spinning when held by the tail, postural instability, and walking in circles. In a few mice, some of these signs appeared within 5 days of nocardial infection. The number of mice presenting motor impairments increased steadily so that by 14 days post-infection, $25 \%$ of the animals had some form of movement abnormalities. Many of these movement disorders were also observed in the animal model of infection with $N$. asteroides (22).

Following injection of $5 \times 10^{6} \mathrm{CFU}$ of log-phase N. otitidiscaviarum (GAM-5) into the tail vein of mice, approximately $10^{3} \mathrm{CFU}$ became localized within the brain, and during the next $24 \mathrm{~h}$ there was a 10 -fold increase in CFU. The number of CFU in the brain then remained constant for about 3 to 4 days, followed by a gradual, but steady, decline so that 14 days after infection the brains appeared to be sterile. Kohbata and Beaman (17) reported a similar growth pattern in the brain of mice following $i v$ injection of logphase cells of $N$. asteroides GUH-2. In both models (GAM-5 and GUH-2), the loss of bacteria in the brain coincided with the appearance of the motor impairments described above. However, in spite of the absence of bacterial CFU in the brain, the neurological manifestations persisted for life in most of the mice.

It is unknown how the mice develop signs of parkinsonism at a time after the apparent elimination of the bacteria from the brain. Even though samples taken from infected mice fail to grow nocardiae, it is unlikely that all of the nocardiae are eliminated from these animals because mycetomas develop in the murine limbs 3 months after infection. These observations suggest that the nocardiae may be present in different regions of the body, including the central nervous system, in some latent or cryptic form. One possible explanation of these observations is that GAM-5 is induced in a "nocardial L-form" which persists in the infected murine brain in a latent form $(19,29)$. A second possible explanation for the development of parkinsonian signs after the apparent elimination of the bacteria might be the result of a release of neurotoxic substances from the nocardial cells as they were killed and cleared from the brain (19). A third possibility for the impaired motor functions may be that the bacterial destruction within the brain releases antigens that might induce an autoimmune response which then provokes the abnormal movements.

Microscopic observations revealed that at $24 \mathrm{~h}$ after nocardial injection, bacterial filaments were localized in the brain parenchyma, extending into neuronal cells near the blood vessels. The frontal and parietal cortex, the SNpc, the VTA, the red and subthalamic nuclei, the thalamus, and the hypothalamus were the brain regions where 
bacteria were more abundant. In most cases no inflammatory response was found to be associated with the presence of bacteria. However, occasionally cortical inflammatory infiltrates were observed in both GUH2- and GAM-5-infected mice, but after a thorough examination, bacteria were not detected within these infiltrates. At the same time, well-developed abscesses were never observed in the brain of any mice following infection with these 2 nocardial species.

Finally, $5-\mu \mathrm{m}$ coronal sections from the brain of mice that presented parkinsonian signs one month after GAM-5 infection had intracytoplasmic hyaline-like inclusion bodies in neurons, mostly in the substantia nigra. These intraneuronal inclusions resembled Lewy bodies $(17,21,30,31)$. Lewy bodies are considered essential for the pathological di- agnosis of PD (3,4). However, similar inclusions have been observed in other diseases like Hallervorden-Spatz disease, parkinsonian-dementia complex of Guam, multiple system atrophy (4), or after aging (1). Whether or not the chemical composition of these intracytoplasmic hyaline-like inclusion bodies observed after $N$. otitidiscaviarum infection is the same as that found in PD remains to be determined.

\section{Acknowledgments}

We are grateful to Jesús Avella-Cale, Unidad de Ultraestructura, Departamento de Patología, Facultad de Medicina, Universidad de Los Andes, Mérida, Venezuela, for technical assistance.

\section{References}

1. Adams RD, Victor M \& Ropper AH (Editors) (1997). Principles of Neurology. McGraw-Hill, New York.

2. Rowland PL (Editor) (1995). Merritt's Textbook of Neurology. Lewis $\&$ Wilkins, New York.

3. Waters CH (Editor) (1999). Diagnosis and Management of Parkinson's Disease. Professional Communications, Caddo, New York.

4. Watts RL \& Koller WC (Editor) (1997). Movement Disorders. Neurologic Principles and Practice. McGraw-Hill, New York.

5. Olanow CW \& Tatton WG (1999). Etiology and pathogenesis of Parkinson's disease. Annual Review of Neuroscience, 22: 123-144.

6. Economo CV (1917). Encephalitis lethargica. Wiener Klinische Wochenschrift, 30: 581-585.

7. Duvoisin RC \& Yahr MD (1965). Encephalitis and parkinsonism. Archives of Neurology, 12: 227-239.

8. Schwartz J \& Elizan TS (1976). Search for viral particles and virusspecific products in idiopathic Parkinson's disease brain material. Annals of Neurology, 6: 261-263.

9. Mattock C, Marmot M \& Stern G (1988). Could Parkinson's disease follow intra-uterine influenza? J oumal of Neurology, Neurosurgery and Psychiatry, 51: 753-756.

10. Fazzini E, Fleming J \& Fahn S (1992). Cerebrospinal fluid antibodies to coronavirus in patients with Parkinson's disease. Movement Disorders, 7: 153-158.

11. Martyn CN (1997). Infection in childhood and neurological diseases in adult life. British Medical Bulletin, 53: 24-39.

12. Pradhan S, Pandey N, Shashank S, Gupta RK \& Mathur A (1999). Parkinsonism due to predominant involvement of substantia nigra in J apanese encephalitis. Neurology, 53: 1781-1786.

13. Calne DB, Duboisin RC \& McGeer E (1984). Speculations on the etiology of Parkinson's disease. Advances in Neurology, 40: 353-
360.

14. Wszolek Z, Monsour H, Smith P \& Pfeiffer R (1988). Cryptococcal meningoencephalitis with parkinsonian features. Movement Disorders, 3: 271-273.

15. Kim J S, Choi IS \& Lee MC (1995). Reversible parkinsonism and dystonia following probable Mycoplasma pneumoniae infection. Movement Disorders, 10: 510-512.

16. Altschuler E (1996). Gastric Helicobacter pylori infection as a cause of idiopathic Parkinson disease and non-arteric anterior optic ischemic neuropathy. Medical Hypotheses, 47: 413-414.

17. Kohbata S \& Beaman BL (1991). L-dopa-responsive movement disorder caused by Nocardia asteroides localized in the brains of mice. Infection and Immunity, 59: 181-191.

18. Beaman BL \& Moring SE (1994). Relationship among cell wall composition, stage of growth, and virulence of Nocardia asteroides GUH-2. Infection and Immunity, 56: 557-563.

19. Beaman BL \& Beaman L (1994). Nocardia species: host-parasite relationships. Clinical Microbiology Reviews, 7: 213-264.

20. Beaman BL (1992). Nocardia: an environmental bacterium possibly associated with neurodegenerative diseases in humans. In Isaacson R \& J ensen KF (Editors), The Vulnerable Brain and Environmental Risks. Plenum Press, New York, 147-166.

21. Beaman BL (2000). The pathogenesis of Nocardia. In: Fischetti VA (Editor), Gram-Positive Pathogens. American Society of Microbiology, Washington, DC, 594-606.

22. Beaman BL (1992). Nocardia as a pathogen of the brain: mechanisms of interactions in the murine brain - a review. Gene, 115: 213217.

23. Ogata SA \& Beaman BL (1992). Adherence of Nocardia asteroides within the murine brain. Infection and Immunity, 60: 1800-1805. 
24. Ogata SA \& Beaman BL (1992). Site-specific growth of Nocardia asteroides in the murine brain. Infection and Immunity, 60: 32623267.

25. Hyland K, Beaman BL, LeWitt P, Andrew J \& DeMaggio J (2000). Monoamine changes in the brain of BALB/C mice following sublethal infection with Nocardia asteroides (GUH-2). Neurochemical Research, 25: 443-448.

26. García E (Editor) (1997). Estudio de la Nocardia otitidiscaviarum: Ultraestructura y Patogenia. Trabajo de Ascenso mimeografado, Universidad de Los Andes, Mérida, Venezuela.

27. Luna LG (Editor) (1979). Manual of Histological Staining Methods of the Armed Forces Institute of Pathology. McGraw-Hill, New York.

28. Bradford MM (1976). A rapid and sensitive method for the quantitation of microgram quantitites of protein utilizing the principle of protein-dye binding. Annals of Biochemistry, 72: 248-254.

29. Beaman BL (1984). The cell wall as a determinant of pathogenicity in Nocardia: the role of L-forms in pathogenesis. In: Ortiz-Ortiz L, Bojalil LF \& Yakoleff V (Editors), Biological, Bichemical and Biomedical Aspects of Actinomycetes. Academic Press, Orlando, FL, USA, 89-104.

30. Beaman BL \& Beaman L (2000). Nocardia asteroides as an invasive, intracellular pathogen of the brain and lungs. In: Oelschlaeger $\&$ Hacker (Editors), Bacterial Invasion into Eukaryotic Cells. Kluwer Academic/Plenum Publishers, New York, 167-197.

31. Beaman BL, Canfield D, Anderson J , Pate B \& Calne D (2000). Sitespecific invasion of the basal ganglia by Nocardia asteroides GUH-2. Medical Microbiology and Immunology, 188: 161-168. 